\title{
1 Tropical arboreal ants form dominance hierarchies over nesting resources in
}

\section{2 agroecosystems.}

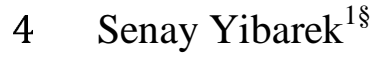

5 Stacy M. Philpott ${ }^{2}$

6

$7{ }^{1}$ Department of Integrative Biology

8 University of California, Berkeley

9 VLSB 5017, Berkeley, California 94720

10

$11{ }^{2}$ Environmental Studies Department

12 University of California, Santa Cruz

131156 High Street

14 Santa Cruz, CA 95064

15

16

17

18 


\section{Abstract}

20 Interspecific dominance hierarchies have been widely reported across animal systems. While

21 some dominant individuals (winners) get to monopolize resources, during dyadic interactions,

22 they can increase their relative fitness as compared to subdominant individuals (losers). In some

23 ant species, dominance hierarchies have been used to explain species coexistence and

24 community structure. However, it remains unclear whether or in what contexts dominance

25 hierarchies occur in tropical ant communities. Furthermore, it can be challenging to infer and

26 quantify reliable dominance hierarchies from observed interactions. This study seeks to examine

27 whether arboreal twig-nesting ants competing for nesting resources in a Mexican coffee

28 agricultural ecosystem are arranged in a dominance hierarchy. Using network analysis, we

29 quantified interactions between ten species by measuring the uncertainty and steepness in the

30 dominance hierarchy. We also assessed the orderliness of the hierarchy by considering species

31 interactions at the network level. Based on the Elo-ranking method, we found that the twig-

32 nesting ant species Myrmelachista mexicana ranked highest in the ranking, while Pseudomyrmex

33 ejectus was ranked as the lowest in the hierarchy. We quantified the uncertainty in the

34 dominance hierarchy and found that the hierarchy was intermediate in its steepness, suggesting

35 that the probability of higher ranked individuals winning contests against lower ranked

36 individuals was fairly high. Motif analysis and significant excess of triads further revealed that

37 the species networks were largely transitive. This study highlights that some tropical arboreal ant

38 communities self-organize into dominance hierarchies.

39

40 Key Words: dominance hierarchy, arboreal ants, competition, networks 


\section{Introduction}

42 A long-standing goal in ecology has been to determine the underlying mechanisms that

43 give rise to species coexistence in local communities, especially in assemblages with multiple

44 competing species (MacArthur 1958; Hutchinson 1959). Numerous mechanisms have been

45 proposed for maintaining species coexistence (Wright 2002; Silvertown 2004). Interspecific

46 competitive trade-offs, whereby the superiority of a particular species in an environment or biotic

47 condition is balanced by the inferiority of other species, can lead to segregation among

48 species (Tilman 1994; Levine et al. 2004). These interspecific interactions are thought to lead to

49 the long-term stable coexistence of ecologically similar species (Levins 1979; Holt et al. 1994;

50 Chesson 2000; Bever 2003; Rudolf and Antonovics 2005), and may also be characterized by

51 dominance hierarchies. Dominance hierarchies have been widely observed in a wide range of

52 taxa, from vertebrates to invertebrates (Chase and Seitz 2011). Species can be ranked into

53 dominant species (i.e. higher-ranked individuals) or subordinate species (i.e. lower-ranked

54 individuals) on the basis of aggression or ritual displays (Drews 1993). Interspecific dominance

55 hierarchies have been used to understand patterns of local species coexistence in ecological

56 communities with as consequence that higher ranked individuals monopolize resources resulting

57 in fitness benefits (Morse 1974; Schoener 1983).

58 In ant communities, dominance hierarchies have been used to examine interspecific

59 tradeoffs to explain species coexistence patterns (Stuble et al. 2013). These trade-offs include the

60 discovery-dominance trade-off, the discovery-thermal tolerance tradeoff, and the discovery-

61 colonization trade-off (Cerdá et al. 1998a; Stanton et al. 2002; Lebrun and Feener 2007; Stuble

62 et al. 2013). In addition to testing interspecific trade-offs, dominance hierarchies have been used

63 to understand the role of dominant species in structuring local communities and composition, 
64 such as partitioning dominant and subdominant species within guilds (Baccaro et al. 2010; Arnan

65 et al. 2012). Dominant ant species play an important role in the structuring of local communities.

66 For example, Formica species dominating a boreal ecosystem divert resources away from

67 subdominant competitors (Savolainen and Vepsäläinen 1988). In Mediterranean ecosystems,

68 subdominant species forage at nearly lethal environmental conditions while dominant species

69 reduce mortality risk by foraging at more favorably temperatures (Cerdá et al. 1998c). In tropical

70 ecosystems, competing arboreal ants can be structured into a dominance hierarchy with higher

71 ranked ant species having greater access to nesting sites and extrafloral nectaries. However,

72 levels of uncertainty associated with outcomes of interspecific interactions are often not

73 quantified (Stuble et al. 2017). Furthermore, its remains unclear how arboreal ants or tropical

74 ants are structured at higher-order interactions, such as when interspecific interactions are

75 viewed as a network.

76 In this study, we examine dominance hierarchies for a community of arboreal twig-

77 nesting ants in a coffee agroecosystem. Both arboreal and ground-dwelling twig-nesting ants in

78 coffee agroecosystems are nest-site limited in terms of number (Philpott and Foster 2005a),

79 diversity (Armbrecht et al. 2004; Gillette et al. 2015), and sizes (Jiménez-Soto and Philpott

80 2015) of nesting resources. Many studies focused on interspecific dominance hierarchies lack a

81 clear and consistent definition of dominance. For twig-nesting ants, nest takeovers are common

82 and nest sites are often limiting, thus dominance in this system is defined as competition for nest

83 sites (Brian 1952), and in at least one case has been experimentally demonstrated (Palmer et al.

$842000 a$ ). Although dominance studies use various methods to rank species, they don't typically

85 account for uncertainty in rankings, except for a few cases (Adler et al. 2007; Stuble et al. 2013).

86 This present study aims to develop dominance hierarchies for twig-nesting ants living in hollow 
87 twigs in a Mexican coffee agricultural ecosystems due to competition for nest resources. We

88 adopt methods from network analysis to infer dominance hierarchies from competitive

89 interactions by estimating uncertainties and steepness in rankings (Pinter-Wollman et al. 2014;

90 Shizuka and McDonald 2015; Sánchez-Tójar et al. 2017). Furthermore, by viewing twig-nesting

91 ants as a network we estimate the orderliness of the hierarchy within the community.

92 Specifically, we tested the hypothesis that tropical, arboreal twig-nesting ants form a clear,

93 dominance hierarchy for nesting sites in controlled environments.

95 Methods

96 Study Site and System

97 We conducted fieldwork at Finca Irlanda $\left(15^{\circ} 20^{\prime} \mathrm{N}, 90^{\circ} 20^{\prime} \mathrm{W}\right)$, a 300 ha, privately owned

98 shaded coffee farm in the Soconusco region of Chiapas, Mexico with 250 shade trees per ha.

99 The farm is located between 900-1100 $\mathrm{m}$ a.s.1. Between 2006-2011, the field site received an

100 average rainfall of $5726 \mathrm{~mm}$ per year with most rain falling during the rainy season between May

101 and October. The farm hosts $\sim 50$ species of shade trees that provide between 30-75\% canopy

102 cover to the coffee bushes below. The farm has two distinct management areas -- one that is a

103 traditional polyculture and the other that is a mixture of commercial polyculture coffee and shade

104 monoculture coffee according to the classification system of (Moguel and Toledo 1999).

105 The arboreal twig-nesting ant community in coffee agroecosystems in Mexico is diverse.

106 There are 40 species of arboreal twig-nesting ants at the study site including Brachymyrmex (3

107 species), Camponotus (8), Cephalotes (2), Crematogaster (5), Dolichoderus (2), Myrmelachista

108 (3), Nesomyrmex (2), Procryptocerus (1), Pseudomyrmex (11), and Technomyrmex (1) (Philpott

109 and Foster 2005a; Livingston and Philpott 2010). 


\section{1 'Real-estate’ experiments}

112 We examined the relative competitive ability of twig-nesting ants by constructing

113 dominance hierarchies based on 'real estate' experiments conducted in the lab. We collected ants

114 during systematic field surveys in 2007, 2009, 2011, and 2012 in the two different areas of the

115 farm, and then used ants in lab experiments. We first removed ants from individual twigs, and

116 then placed ants (workers, alates, and brood) from two different species (one twig per species)

117 into sealed plastic tubs with one empty artificial nest. The artificial nest, or 'real estate',

118 consisted of a bamboo twig, $120 \mathrm{~mm}$ long with a 3-4 mm opening. After 24 hours, we opened

119 the bamboo twigs to note which species had colonized the twig. All ants collected were used in

120 'real estate' trials within two days of collection, or were discarded.

121 We conducted trials between pairs of the ten most common ant species encountered

122 during surveys: Camponotus abditus, Camponotus (Colobopsis) sp. 1, Myrmelachista mexicana,

123 Nesomyrmex echinatinodis, Procryptocerus scabriusculus, Pseudomyrmex ejectus,

124 Pseudomyrmex elongatus, Pseudomyrmex filiformis, Pseudomyrmex PSW-53, and

125 Pseudomyrmex simplex. We selected a priori to use the 10 most common species. We intended to

126 replicate trials for each pair (out of a total of 45 two-species pairs) at least ten times. However,

127 low encounter rates for some species, and for pairs of species within two days of one another

128 precluded obtaining ideal sample sizes. We replicated trials for each species pair on average 5.73

129 times; four species pairs were replicated once, nine species pairs were replicated twice, and 31

130 species pairs were replicated three or more times. Only one species pair (M. mexicana and $P$.

131 filiformis) was not tested. We conducted 42 trials in 2007, 105 trials in 2009, 82 trials in 2011,

132 and 30 trials in 2012 for a total of 259 trials. 


\section{Dominance interactions}

135 We used our ant dataset to infer a dominance hierarchy by simulating interactions among

136 individuals to estimate level of uncertainty and steepness in the hierarchy. All simulations were

137 conducted in $\mathrm{R}$ version 3.3.3 (R Core Development Team 2017). We used the R package

138 “animDom" version 0.1.2 to infer dominance hierarchies using the randomized Elo-rating

139 method (Sánchez-Tójar et al. 2017). The R package 'statnet' was used to test triangle transitivity

140 measures (Handcock et al. 2008).

141 We subsampled the observed data to determine if the population had been adequately

142 sampled to infer reliable dominance hierarchies. We calculated the ratio of interactions to

143 individuals to determine sampling effort. An average sampling effort ranging from 10-20

144 interactions is sufficient to infer hierarchies in empirical networks (McDonald and Shizuka

145 2013). Furthermore, we compared the proportion of observed dyads to the expected proportion

146 of dyads with the probability of interactions of equal group size following a Poisson distribution

147 (Sánchez-Tójar et al. 2017). We estimated the dominance hierarchy using the random Elo-rating

148 method in order to track ranking dynamics over time. We converted the observation data and

149 randomized the order in which sequences of interactions occurred $(n=1000)$ such that different

150 individual Elo-ratings were calculated each time to obtain mean rankings (Neumann et al. 2011;

151 Strandburg-Peshkin et al. 2015). We estimated uncertainty in the hierarchy by splitting our

152 dataset into two halves and estimated whether the hierarchy in one half of the matrix correlated

153 with the hierarchy of the other half in the matrix (Sánchez-Tójar et al. 2017).

154 In addition to examining the role of individual ant attributes and levels of uncertainty in

155 dominance hierarchies, we were interested in assessing how the organization of linear dominance 
156 hierarchies emerged at higher levels. While individual attributes of species serve as a good

157 predictor of dominance hierarchies among dyadic pairs, the pattern becomes less clear when

158 seeking to explain linear dominance hierarchies at higher levels of species interactions (Chase

159 and Seitz 2011). Therefore, we examined the formation of dominance hierarchies using motif

160 analysis to identify network structures composed of transitive and cyclical triads (Faust 2007).

161 Motif analysis is commonly used in social network analysis to detect emergent properties of the

162 network structure as an explanation for dominance hierarchies by comparing the relative

163 frequencies of motifs in the observed network to the expected value for the null hypothesis of a

164 random network (Holland and Leinhardt 1972; Faust 2007). We carried out motif analysis with

165 customized randomization procedures (McDonald and Shizuka 2013) to compare the structure of

166 our network model against random network graphs. Species interaction data were represented as

167 a directional outcome matrix. The nodes in the network represent individual ant species and the

168 one-way directional arrows of the edges represent dominant-subordinate relationships. In the

169 random networks, we maintained the same number of nodes and edges as in the observed

170 network, but the directionality and placement of edges were generated randomly. Using the

171 adjacency matrix, we calculated the triad census (McDonald \& Shizuka 2012). The triad census

172 allows us to examine directed species interactions (Pinter-Wollman et al. 2011). We used the

173 seven possible triad configurations fully composed of three nodes that either have asymmetric or

174 mutual edges (Holland and Leinhardt 1972). We used the network analysis packages 'statnet'

175 (Handcock et al. 2008) and 'Igraph' (Csardi and Nepusz 2006) in R (R Core Development Team

176 2017) to calculate the frequencies of triad configurations (total triads $=220$ ) and to compare the

177 observed $(\mathrm{N}=10)$ to the random network graphs $(\mathrm{N}=10)$. 
To test for statistical significance between the observed and randomly generated

179 networks, we computed the triangle transitivity $\left(t_{t r i}\right)$. Although the triad census consists of 8

180 different triangle configurations, we focus our attention on the relative frequencies of transitive

181 triangles. The proportion of transitive triangles $\mathrm{P}(\mathrm{t})$ in a dominance network is given by:

$$
P(t)=\frac{N_{\text {transitive }}}{N_{\text {transitive }}+N_{\text {intransitive }}}
$$

185 In this case, the expected probability of a transitive triangle in a random network is $\mathrm{P}(\mathrm{t})=0.75$.

186 Using our expected value, we use a scaled index $T_{t r i}$ ranging from 0 as the random expectation

187 to 1 where all triangles are transitive in the network. In random networks the expected frequency

188 of transitive triangles is 0.75 . For each empirical network, we simulate 1000 random graphs and

189 calculate the $T_{t r i}$ each time. The P-value represents the number of times the randomized $T_{t r i}$ is

190 greater than the $T_{t r i}$ value of the observed network (Shizuka and McDonald 2012).

192 Results

\section{3 'Real estate’ experiments.}

194 In all 258 of 259 trials, there was a clear winner of the 'real estate' battle after 24 hours,

195 meaning that one of the two species had occupied the artificial nest. From examining the wins

196 and losses, a clear hierarchy emerged, with some species winning the vast majority (>70\%) of

197 trials in which they were involved, and other species winning few trials $(<30 \%)$. The ranking

198 shows that the twig-nesting species Myrmelachista mexicana is the highest ranked species, while

199 Pseudomyrmex ejectus is the lowest ranked species in the hierarchy (Table 1). The one trial that

200 did not result in a winner was a trial involving P. elongatus and P. ejectus. 
Dyadic interactions: Estimating Uncertainty in Dominance Hierarchy

204 interaction to individuals (25.8) shows an adequate sampling effort beyond the 10-20

205 recommended range (Sánchez-Tójar et al. 2017). Using the randomized Elo-rating method, we

206 found that the shape of the hierarchy was intermediate in its steepness showing that rank in the

207 hierarchy largely predicts the probability of winning an interaction (Fig 1). We quantify this by

208 using the Elo-rating repeatability and found a steepness of 0.938 .

209 We further estimated the uncertainty in the hierarchy by splitting the database into two,

210 and estimating whether hierarchy from one half resembles the hierarchy estimated from the other

211 half. We find that the degree of uncertainty/steepness in the hierarchy is intermediate

$212 \quad($ mean $=0.76,2.5 \%$ and $97.5 \%$ quantile $=(0.50,0.94))$.

214 Triad census analysis.

215 The triad census analysis of the triad distribution showed that the observed network has a

216 significant excess of transitive triads $(\mathrm{N}=76)$ followed by a significant deficit of cyclical triads

217 (N=8). Triad types that are positive (i.e. non-overlapping at 0 ) occurred in excess in the observed

218 network, while triad types that are negative showed a deficit in the observed network as

219 compared to the random null network (Fig 2).

220 The remaining five triads in the network did not show any significant differences in the

221 mean triad percentage rates between the observed and expected network. While the data showed

222 a clear excess of transitive triangles (34.55\%) and deficit for cyclical triangles (3.6\%), the 
223 distribution for pass-along triads shows a less typical pattern with the $95 \%$ confidence intervals

224 crossing the zero line but the mean percentage still showing a deficit.

\section{Discussion}

228 system. We found that M. mexicana was ranked the highest, using Elo-rating method, while $P$.

229 ejectus species ranked the lowest in the hierarchy. We further estimated the level of uncertainty

230 associated with the hierarchy and found an intermediate level of steepness in dominance

231 suggesting a relatively stable hierarchy. The randomized Elo-rating repeatability was 0.93 and

232 remained very stable independently of the ratio of interactions to individuals. To verify that this

233 pattern was not due to a lack of sampling effort, we correlated the two halves of the interaction

234 dataset and found that our sampling effort was 25.8, falling above the minimal recommended

235 range of 10-20 species. Overall, we find that the probability of a higher ranked individual

236 winning a contest against a lower ranked is relatively high, which corroborates our qualitative

237 finding of the hierarchy steepness. Motif analysis of the network further revealed a significant

238 excess of transitive interactions. Thus, the degree of orderliness in the hierarchy is maintained at

239 higher levels of interactions, or in other words, dominance is relatively linear, and transitive,

240 indicating that there is a strong, structured hierarchy in nest-site competition for arboreal twig-

241 nesting ants in coffee agroecosystems.

242 A question stemming from these results is what effect this might have on structuring the

243 distribution and relative abundance patterns of ants under natural conditions. In Mediterranean

244 ecosystems, dominant and subordinate ants are partitioned on the basis of their life-history traits

245 (Arnan et al. 2012). Dominant ant species had more abundant colonies and displayed increased 
246 defense for resources in contrast to subordinate ant species. Meanwhile, subordinate ants

247 exemplified greater tolerance to higher temperatures (Cros et al. 1997; Cerdá et al. 1998b). The

248 outcome of interspecific interactions within the dominance hierarchy was contingent on

249 environmental conditions (Arnan et al. 2012). In a temperate forest ecosystem of North Carolina,

250 dominance was context dependent (Stuble et al. 2017). Rankings on the basis of bait

251 monopolization revealed that dominance correlated positively with relative abundances since the

252 most abundant species were ranked higher in the dominance hierarchy. In contrast, rankings

253 based on aggressive encounters did not correlate with abundance. In some habitats, dominance

254 patterns are largely determined by the time of day that foraging occurs (Cerdá et al. 1998b;

255 Bestelmeyer 2000). In the North Carolina system, the most abundant ant species Aphaenogaster

256 rudis was most active during the morning hours, whereas the cold-tolerant Prenolepis imparis

257 species was dominant during the night hours (Stuble et al. 2017). The ranking of species also

258 depends on the size of resources. In an assemblage of woodland ants, smaller-sized ants were

259 more efficient at acquiring and transporting fixed resources. Bigger sized solitary ants excelled at

260 retrieving smaller food that were mobile during competitive interactions. However, the

261 introduction of phorid parasitoids in this system reduced the transitive hierarchy facilitating the

262 coexistence of subdominant ants (LeBrun 2005; Lebrun and Feener 2007). In our study on

263 competition for nesting sites in the lab, we were able to used fixed resources and to a certain

264 degree control variation in colony size.

265 Regardless of the ecological factors driving dominance hierarchies under natural

266 conditions, it's important to note that ranking methods vary considerably among studies (Stuble

267 et al. 2013). Traditionally, field studies have quantified dominance relationships on the basis of

268 proportion of contests won. Other studies have use more sophisticated methods to account for 
269 competitive reversals (Vries 1998) or have updated rankings based on relative wins and losses

270 during contests (Colley 2002). In this study, we used the Elo-rating by randomizing the sequence

271 of interactions and calculating the mean of individual Elo-ratings (Sánchez-Tójar et al. 2017). By

272 calculating the repeatability of the individual Elo-rankings, we estimated the uncertainty in the

273 rankings by obtaining confidence intervals for each species. This uncertainty measure has

274 allowed us to detect an intermediate dominance hierarchy. By further considering ant

275 communities as networks of interacting species, we have found that twig-nesting ants are

276 overwhelming self-organized into a transitive dominance hierarchy.

More broadly, a high proportion of stable transitive relations have been observed in other

278 animal systems for both dyadic and triadic level interactions (McDonald and Shizuka 2013;

279 Shizuka and McDonald 2015). For example, dominance contest over free-ranging African

280 elephants in Kenya showed that between-group dominance structure is highly transitive

281 (Wittemyer and Getz 2007). Despite the wide geographical distribution of resources and

282 infrequent contests among elephants, the potential cost for conflict were sufficiently high

283 resulting in strong winner and loser effects. Among wild chimpanzees, both male and females

284 formed dominance hierarchies. However, for high ranking female chimpanzees, dominances was

285 associated with reproductive fitness due to greater access to food resources (Wittig and Boesch

286 2003). Miller et al. 2017 partnered with citizen scientists to examine social hierarchies among

287 bird species at the continental scale. They used extensive catalogs of interspecific interactions at

288 bird feeders across North America and observed that, across the continent, birds at feeders

289 formed a linear dominance hierarchy encompassing an ecologically diverse range of species.

290 Social dominance within a hierarchy was found to be strongly associated with body size with

291 higher ranked species having preferential access to food resources at feeders. 
While our study shows that nest site competition is important for structuring twig-nesting

293 ant communities, dominance hierarchies are often context-dependent and ranking of the same

294 species varies across geographical regions or disturbance regimes (Andersen 1997; Feener et al.

295 2008, Sensenig et al. 2017). Previous research involving ant competition for variable resources

296 in temperate ecosystems showed that intransitive competition at local spatial scales mediates ant

297 coexistence (Sanders and Gordon 2003). Microclimatic factors also disrupt dominance

298 hierarchies (Cerdá et al. 1998b). For instance, environmental variation in agricultural coffee

299 systems is likely to influence dominance hierarchies (Philpott and Foster 2005a; Perfecto and

300 Vandermeer 2011). Likewise, occurrence of fire can disrupt dominance hierarchies in specialist

301 ants in Acacia trees resulting in increased abundance of subordinate ants (Sensenig et al. 2017)

302 Further, top down processes such as predation and parasitism are likely to mediate twig-nesting

303 ant competition in natural communities (Philpott et al. 2004; Feener et al. 2008b; Hsieh and

304 Perfecto 2012). In addition, competition and disturbance from ground- and carton-nesting ants

305 may influence the colonization and community composition of arboreal twig-nesting ants

306 (Philpott et al. 2004a; Ennis and Philpott 2017). Therefore, more comparative research is needed

307 to examine how geographical differences or disturbance affects the hierarchy and ultimately the

308 distribution and relative abundance of different arboreal, twig-nesting ant species.

A myriad of other factors may drive the distribution and relative abundance of arboreal

310 ants (Yamaguchi 1992a; Palmer et al. 2000a). Variation in life-history trade-offs can influence

311 dominance patterns. For example, competition-colonization trade-offs have been identified

312 between competitive colonies expanding unto nearby trees and foundress queens establishing

313 new nest sites (Stanton et al. 2002a). Twig-ant communities are strongly influenced by canopy

314 structure and habitat complexity (Philpott et al. 2018). Tree size correlates positively with ant 
315 abundance (Yusah and Foster 2006), species richness (Klimes et al. 2015), and composition

316 (Dejean et al. 2008). Canopy connectivity, in turn, impacts local species coexistence as lower

317 connectivity decreases species richness (Powell et al. 2011). Canopy connections serve as

318 pathways by which arboreal ants access tree resources. Limited access to nesting cavities

319 hampers growth and reproduction of arboreal ants (Philpott and Foster 2005). Differences in nest

320 entrances can affect both the abundance and richness of arboreal ant species that are competing

321 for cavities resources (Jiménez $\square$ Soto and Philpott 2015). A study examining the effects of twig

322 diversity on litter-nesting ant species found that twigs derived from different trees species

323 harbored greater ant diversity as compared to twigs obtained from a single tree species

324 (Armbrecht et al. 2004). In some ant species belonging to the genus Cephalotes, ant size and nest

325 entrance size impacted survival and colony fitness (Powell 2009). Although our artificial twigs

326 featured standardized cavity entrances, variations in ant sizes and cavity entrance size in natural

327 conditions will be important in determining arboreal ant dominance. Thus, future studies should

328 consider variation in nest entrance size to guide our understanding in twig dominance

329 hierarchies.

Based on our findings, we find that tropical twig-nesting ants competing for nesting

331 resources are arranged in a dominance hierarchy. We find that the arboreal ants Myrmelachista

332 mexicana was the highest ranked species in the hierarchy, while Pseudomyrmex ejectus was

333 ranked as the lowest in the hierarchy. To more reliably infer a hierarchy in our dataset, we

334 accounted for uncertainty in the hierarchy by estimating the probability that a higher ranked

335 defeats a subordinate species. We found that an intermediate steepness level characterized the

336 hierarchy after corroborating an adequate sampling effort. Moving beyond simple pair-wise

337 interactions, we used motif analysis to infer higher order interactions. Transitive interactions 
were significantly over-represented in the network which further illustrates that twig-nesting ants

339 are organized in a linear hierarchy. While we find that twig-nesting ants form a dominance

340 hierarchy in this tropical agricultural system, it's likely to expect variation in domination patterns

341 across ecosystems and habitats. Subsequent studies should link dominance patterns with relative

342 abundance patterns in the field in order to assess if particular species traits are important in

343 structuring local communities. While competitive outcomes in our experiment are static (winner

344 and loser), dominance hierarchies exhibit considerable variation and field studies should

345 therefore include spatial and temporal variation. Dominance hierarchy studies are typically

346 designed to assess antagonistic interactions, but less focus has been placed on collecting data

347 with neutral interactions. Difference in food preference and temporal foraging patterns suggest

348 that species don't necessarily interact in an antagonistic fashion. Therefore, more studies noting

349 neutral interactions will shed greater light on the prevalence of dominance hierarchies under

350 natural conditions.

352 Acknowledgements

353 The following people assisted with field and lab data collection: G. Domínguez Martínez, U.

354 Perez Vasquez, G. Lopez Bautista, F. Sanchez-Lopez, D. Lopez, P. Bichier, B. Chilel, A. De la

355 Mora, D. Gonthier, G. Livingston, K. Mathis, K. Ennis, E. Jimenez-Soto, J. Vandermeer, I.

356 Perfecto, D. Jackson, H. Hsieh, and A. Iverson. J. Rojas and E. Chamé Vasquez of El Colegio de

357 la Frontera Sur (ECOSUR) provided logistical support. Permission for arthropod collection was

358 granted by SEMARNAT (Secretaria de Medio Ambiente y Recursos Naturales). We thank Finca

359 Irlanda and Don Walter Peters for access to the farm and housing for field research. We also

360 wish to thank the participants of the NIMBios workshop on "Animal Social Networks". Funding 
362 Grant to SY.

\section{Data Accessibility}

365 Twig-ant competition data and scripts to calculate dominance rankings are available via github

366 https://github.com/shenii/twignesting_dominance_dataset

\section{References}

369 Adler, F. R., E. G. LeBrun, D. H. Feener Jr., A. E. P. Nonacs, and E. D. L. DeAngelis. 2007.

374 Armbrecht, I., I. Perfecto, and J. Vandermeer. 2004. Enigmatic Biodiversity Correlations: Ant

375 Diversity Responds to Diverse Resources. Science 304:284-286.

376 Arnan, X., X. Cerdá, and J. Retana. 2012. Distinctive life traits and distribution along

377 environmental gradients of dominant and subordinate Mediterranean ant species. Oecologia

$378 \quad 170: 489-500$.

379 Baccaro, F. B., S. M. Ketelhut, and J. W. D. Morais. 2010. Resource distribution and soil

380 moisture content can regulate bait control in an ant assemblage in Central Amazonian forest.

381 Austral Ecology 35:274-281.

382 Bestelmeyer, B. T. 2000. The trade-off between thermal tolerance and behavioural dominance in 383 a subtropical South American ant community. Journal of Animal Ecology 69:998-1009.

384 Bever, J. D. 2003. Soil community feedback and the coexistence of competitors: conceptual 385 frameworks and empirical tests. New Phytologist 157:465-473.

386 Brian, M. V. 1952. The Structure of a Dense Natural Ant Population. Journal of Animal Ecology $387 \quad 21: 12-24$.

388 Cerdá, X., J. Retana, and A. Manzaneda. 1998a. The Role of Competition by Dominants and 389 Temperature in the Foraging of Subordinate Species in Mediterranean Ant Communities.

390 Oecologia 117:404-412.

$391-1998 b$. The role of competition by dominants and temperature in the foraging of 
subordinate species in Mediterranean ant communities. Oecologia 117:404-412.

$393-1998 c$. The role of competition by dominants and temperature in the foraging of

394 subordinate species in Mediterranean ant communities. Oecologia 117:404-412.

395 Chase, I. D., and K. Seitz. 2011. Chapter 4 - Self-Structuring Properties of Dominance

396 Hierarchies: A New Perspective. Pages 51-81 in R. Huber, D. L. Bannasch, and P. Brennan, eds.

397 Advances in Genetics, Aggression (Vol. 75). Academic Press.

398 Chesson, P. 2000. Mechanisms of Maintenance of Species Diversity. Annual Review of Ecology 399 and Systematics 31:343-366.

400 Colley, W. 2002. Colley's bias free college football ranking method.

401 Cros, S., X. CERDÁ, and J. RETANA. 1997. Spatial and temporal variations in the activity 402 patterns of Mediterranean ant communities. Écoscience 4:269-278.

403 Csardi, G., and T. Nepusz. 2006. The igraph software package for complex network research. 404 InterJournal Complex Systems:1695.

405 Dejean, A., J. Grangier, C. Leroy, J. Orivel, and M. Gibernau. 2008. Nest site selection and induced response in a dominant arboreal ant species. Naturwissenschaften 95:885-889.

Drews, C. 1993. The Concept and Definition of Dominance in Animal Behaviour. Behaviour 125:283-313.

Ennis, K. K., and S. M. Philpott. 2017. Strong influences of a dominant, ground-nesting ant on recruitment, and establishment of ant colonies and communities. Biotropica 49:521-530.

411 Faust, K. 2007. Very Local Structure in Social Networks. Sociological Methodology 37:209412256.

413 Feener, D. H., M. R. Orr, K. M. Wackford, J. M. Longo, W. W. Benson, and L. E. Gilbert. $4142008 a$. Geographic variation in resource dominance-discovery in brazilian ant communities. 415 Ecology 89:1824-1836.

$416-2008 b$. Geographic variation in resource dominance-discovery in Brazilian ant 417 communities. Ecology 89:1824-1836.

418 Gillette, P. N., K. K. Ennis, G. D. Martínez, and S. M. Philpott. 2015. Changes in Species 419 Richness, Abundance, and Composition of Arboreal Twig-nesting Ants Along an Elevational 420 Gradient in Coffee Landscapes. Biotropica 47:712-722.

421 Handcock, M. S., D. R. Hunter, C. T. Butts, S. M. Goodreau, and M. Morris. 2008. Software

422 tools for the Statistical Modeling of Network Data. Journal of Statistical Software 24:1545-7660.

423 Holland, P. W., and S. Leinhardt. 1972. Holland and Leinhardt Reply: Some Evidence on the 424 Transitivity of Positive Interpersonal Sentiment. American Journal of Sociology 77:1205-1209.

425 Holt, R. D., J. Grover, and D. Tilman. 1994. Simple Rules for Interspecific Dominance in 
426 Systems with Exploitative and Apparent Competition. The American Naturalist 144:741-771.

427 Hsieh, H.-Y., H. Liere, E. J. Soto, and I. Perfecto. 2012. Cascading trait-mediated interactions induced by ant pheromones. Ecology and Evolution 2:2181-2191.

429 Hsieh, H.-Y., and I. Perfecto. 2012. Trait-Mediated Indirect Effects of Phorid Flies on Ants. 430 Psyche: A Journal of Entomology 2012:e380474.

431 Hutchinson, G. E. 1959. Homage to Santa Rosalia or Why Are There So Many Kinds of 432 Animals? The American Naturalist 93:145-159.

433 Jiménez-Soto, E., and S. M. Philpott. 2015. Size matters: nest colonization patterns for twig434 nesting ants. Ecology and Evolution 5:3288-3298.

435 Klimes, P., P. Fibich, C. Idigel, and M. Rimandai. 2015. Disentangling the Diversity of Arboreal 436 Ant Communities in Tropical Forest Trees. PLOS ONE 10:e0117853.

437 LeBrun, E. G. 2005. Who Is the Top Dog in Ant Communities? Resources, Parasitoids, and 438 Multiple Competitive Hierarchies. Oecologia 142:643-652.

439 Lebrun, E. G., and D. H. Feener. 2007. When trade-offs interact: balance of terror enforces 440 dominance discovery trade-off in a local ant assemblage. Journal of Animal Ecology 76:58-64.

441 Levine, J. M., P. B. Adler, and S. G. Yelenik. 2004. A meta-analysis of biotic resistance to exotic 442 plant invasions. Ecology Letters 7:975-989.

443 Levins, R. 1979. Coexistence in a Variable Environment. The American Naturalist 114:765-783.

444 Livingston, G. F., and S. M. Philpott. 2010. A metacommmunity approach to co-occurrence 445 patterns and the core-satellite hypothesis in a community of tropical arboreal ants. Ecological 446 Research 25:1129-1140.

447 MacArthur, R. H. 1958. Population Ecology of Some Warblers of Northeastern Coniferous 448 Forests. Ecology 39:599-619.

449 McDonald, D. B., and D. Shizuka. 2013. Comparative transitive and temporal orderliness in 450 dominance networks. Behavioral Ecology 24:511-520.

451 Miller, E. T., D. N. Bonter, C. Eldermire, B. G. Freeman, E. I. Greig, L. J. Harmon, C. Lisle, et 452 al. 2017. Fighting over food unites the birds of North America in a continental dominance 453 hierarchy. Behavioral Ecology 28:1454-1463.

454 Moguel, P., and V. M. Toledo. 1999. Biodiversity Conservation in Traditional Coffee Systems of 455 Mexico. Conservation Biology 13:11-21.

456 Morse, D. H. 1974. Niche Breadth as a Function of Social Dominance. The American Naturalist $457 \quad 108: 818-830$.

458 Neumann, C., J. Duboscq, C. Dubuc, A. Ginting, A. Irwan, and A. Widdig. 2011. Assessing 459 dominance hierarchies: validation and advantages of progressive evaluation with Elo-rating. 
Animal Behaviour 82:911-921.

461 Palmer, T. M., T. P. Young, M. L. Stanton, and E. Wenk. 2000a. Short-Term Dynamics of an Acacia Ant Community in Laikipia, Kenya. Oecologia 123:425-435.

463 Palmer, T. M., T. P. Young, M. L. Stanton, and E. Wenk. 2000b. Short-term dynamics of an acacia ant community in Laikipia, Kenya. Oecologia 123:425-435.

465 Perfecto, I., and J. Vandermeer. 2002. Quality of Agroecological Matrix in a Tropical Montane Landscape: Ants in Coffee Plantations in Southern Mexico. Conservation Biology 16:174-182.

467 . 2011. Discovery Dominance Tradeoff: the Case of Pheidole Subarmata and Solenopsis 468 Geminata (Hymenoptera: Formicidae) in Neotropical Pastures. Environmental Entomology 469 40:999-1006.

470 Philpott, S. M., and P. F. Foster. 2005a. Nest-Site Limitation in Coffee Agroecosystems:

471 Artificial Nests Maintain Diversity of Arboreal Ants. Ecological Applications 15:1478-1485.

$472-2005 b$. Nest-site limitation in coffee agroecosystems: artificial nests maintain diversity 473 of arboreal ants. Ecological Applications 15:1478-1485.

474 Philpott, S. M., J. Maldonado, J. Vandermeer, and I. Perfecto. 2004a. Taking trophic cascades up 475 a level: behaviorally-modified effects of phorid flies on ants and ant prey in coffee 476 agroecosystems. Oikos 105:141-147.

$477-2004 b$. Taking trophic cascades up a level: behaviorally-modified effects of phorid flies 478 on ants and ant prey in coffee agroecosystems. Oikos 105:141-147.

479 Philpott, S. M., Z. Serber, and A. De la Mora. 2018. Influences of Species Interactions With 480 Aggressive Ants and Habitat Filtering on Nest Colonization and Community Composition of 481 Arboreal Twig-Nesting Ants. Environmental Entomology 47:309-317. Waters, et al. 2014. The dynamics of animal social networks: analytical, conceptual, and theoretical advances. Behavioral Ecology 25:242-255.

485 Powell, S. 2009. How ecology shapes caste evolution: linking resource use, morphology, performance and fitness in a superorganism. Journal of Evolutionary Biology 22:1004-1013.

487 Powell, S., A. N. Costa, C. T. Lopes, and H. L. Vasconcelos. 2011. Canopy connectivity and the 488 availability of diverse nesting resources affect species coexistence in arboreal ants. Journal of 489 Animal Ecology 80:352-360.

490 R Core Development Team. 2017. R: A language and environment for statistical computing. R 491 Foundation for Statistical Computing.

492 Rudolf, V. H. W., and J. Antonovics. 2005. Species Coexistence and Pathogens with 493 Frequency-Dependent Transmission. The American Naturalist 166:112-118. 
494 Sánchez-Tójar, A., J. Schroeder, and D. R. Farine. 2017. A practical guide for inferring reliable

495 dominance hierarchies and estimating their uncertainty. Journal of Animal Ecology 87:594-608.

496 Sanders, N. J., and D. M. Gordon. 2003. Resource-Dependent Interactions and the Organization 497 of Desert Ant Communities. Ecology 84:1024-1031.

498 Savolainen, R., and K. Vepsäläinen. 1988. A Competition Hierarchy among Boreal Ants: Impact on Resource Partitioning and Community Structure. Oikos 51:135-155.

500 Schoener, T. W. 1983. Field Experiments on Interspecific Competition. The American Naturalist $501 \quad 122: 240-285$.

502 Sensenig, R. L., D. K. Kimuyu, J. C. R. Guajardo, K. E. Veblen, C. Riginos, and T. P. Young. 503 2017. Fire disturbance disrupts an acacia ant-plant mutualism in favor of a subordinate ant

504 species. Ecology 98:1455-1464.

505 Shizuka, D., and D. B. McDonald. 2012. A social network perspective on measurements of 506 dominance hierarchies. Animal Behaviour 83:925-934.

507 2015. The network motif architecture of dominance hierarchies. Journal of The Royal 508 Society Interface 12:20150080.

509 Silvertown, J. 2004. Plant coexistence and the niche. Trends in Ecology \& Evolution 19:605510611.

511 Stanton, M. L., T. M. Palmer, and T. P. Young. 2002a. Competition-Colonization Trade-Offs in 512 a Guild of African Acacia-Ants. Ecological Monographs 72:347-363.

513 2002b. Competition-colonization trade-offs in a guild of african acacia-ants. Ecological 514 Monographs 72:347-363.

515 Strandburg-Peshkin, A., D. R. Farine, I. D. Couzin, and M. C. Crofoot. 2015. Shared decision516 making drives collective movement in wild baboons. Science 348:1358-1361.

517 Stuble, K., I. Juric, X. Cerda, and N. Sanders. 2017. Dominance hierarchies are a dominant 518 paradigm in ant ecology (Hymenoptera: Myrmecological News 24:71-81.

519 Stuble, K. L., M. A. Rodriguez-Cabal, G. L. McCormick, I. Jurić, R. R. Dunn, and N. J. Sanders. 520 2013. Tradeoffs, competition, and coexistence in eastern deciduous forest ant communities.

521 Oecologia 171:981-992.

522 Tilman, D. 1994. Competition and Biodiversity in Spatially Structured Habitats. Ecology 75:252316.

524 Vandermeer, J., I. Perfecto, and S. Philpott. 2010. Ecological complexity and pest control in 525 organic coffee production: uncovering an autonomous ecosystem service. BioScience, Oxford 526 University Press 60:527-537.

527 Vries, H. de. 1998. Finding a dominance order most consistent with a linear hierarchy: a new 
528 procedure and review. Animal Behaviour 55:827-843.

529 Wittemyer, G., and W. M. Getz. 2007. Hierarchical dominance structure and social organization

530 in African elephants, Loxodonta africana. Animal Behaviour 73:671-681.

531 Wittig, R. M., and C. Boesch. 2003. Food Competition and Linear Dominance Hierarchy Among 532 Female Chimpanzees of the Taï National Park. International Journal of Primatology 24:847-867.

533 Wright, J. S. 2002. Plant diversity in tropical forests: a review of mechanisms of species

534 coexistence. Oecologia 130:1-14.

535 Yamaguchi, T. 1992. Interspecific interference for nest sites between Leptothorax congruous and 536 Monomorium intrudens. Insectes Sociaux 39:117-127. 


\section{Figures \& Tables.}

556 Table 1. Estimation of dominance hierarchy using Elo-rating method. Using 10 ant species

557 in the competition experiments, we recorded a total of 258 interactions. The ratio of interactions

558 to species indicates that the sampling effort of 25.8 falls within the minimum 10-20 range. The

559 ranking shows that the twig-nesting species Myrmelachista mexicana is the highest ranked

560 species, while Pseudomyrmex ejectus is the lowest ranked species in the hierarchy. Species are as

561 follows: Myrm (Myrmelachista mexicana), Ps53 (Pseudomyrmex PSW-53), Neso (Nesomyrmex

562 echinatinodis), Ca.ab. (Camponotus abditus), Ca.n. (Camponotus colobopsis), Psfili

563 (Pseudomyrmex filiformis), Pssimp (Pseudomyrmex simplex), Procryp (Procryptocerus

564 scabriusculus), Pselong (Pseudomyrmex elongatus), Psej (Pseudomyrmex ejectus).

\begin{tabular}{|l|l|l|l|l|l|l|l|l|l|l|l|}
\hline \multicolumn{10}{|c}{ Table 1. Estimation of dominance hierarchy using Elo-rating method } \\
\hline \multirow{3}{*}{ Species } & $\begin{array}{l}\text { Myrmecalista } \\
\text { mexicana }\end{array}$ & $\begin{array}{l}\text { Pseudomyrmex } \\
\text { (PSW-53) }\end{array}$ & $\begin{array}{l}\text { Nesomyrmex } \\
\text { echinatinodis }\end{array}$ & $\begin{array}{l}\text { Camponotus } \\
\text { abditus }\end{array}$ & $\begin{array}{l}\text { Camponotus } \\
\text { colobopsis }\end{array}$ & Pseudomyrmex & Psilfourmis & Psimplomyrmex & Procryptocerus & Pseudomyrmex & Pseudomyrn \\
Rankings & 1.105 & 2.290 & 2.792 & 4.445 & 5.231 & 5.375 & 7.579 & 8.081 & 8.154 & 9.948 \\
\hline
\end{tabular}


571 Figure 1. The probability of a higher ranked individual winning. The shape of the hierarchy

572 indicates that the rank is intermediate. We quantified the uncertainty/steepness of the hierarchy

573 based on Elo-rating repeatability which is independent of group size and the ratio of interactions

574 to individuals (Sanchez-Tojar et al. 2017). Based on the Elo-rating, we find that the value

575 obtained is 0.938 which corroborates our qualitative results showing that the hierarchy is

576 intermediate. Thus, rank in this network is a relatively good predictor that a higher ranked

577 individual is more like to win from lower-ranked individuals even though that is not always the

578 case.

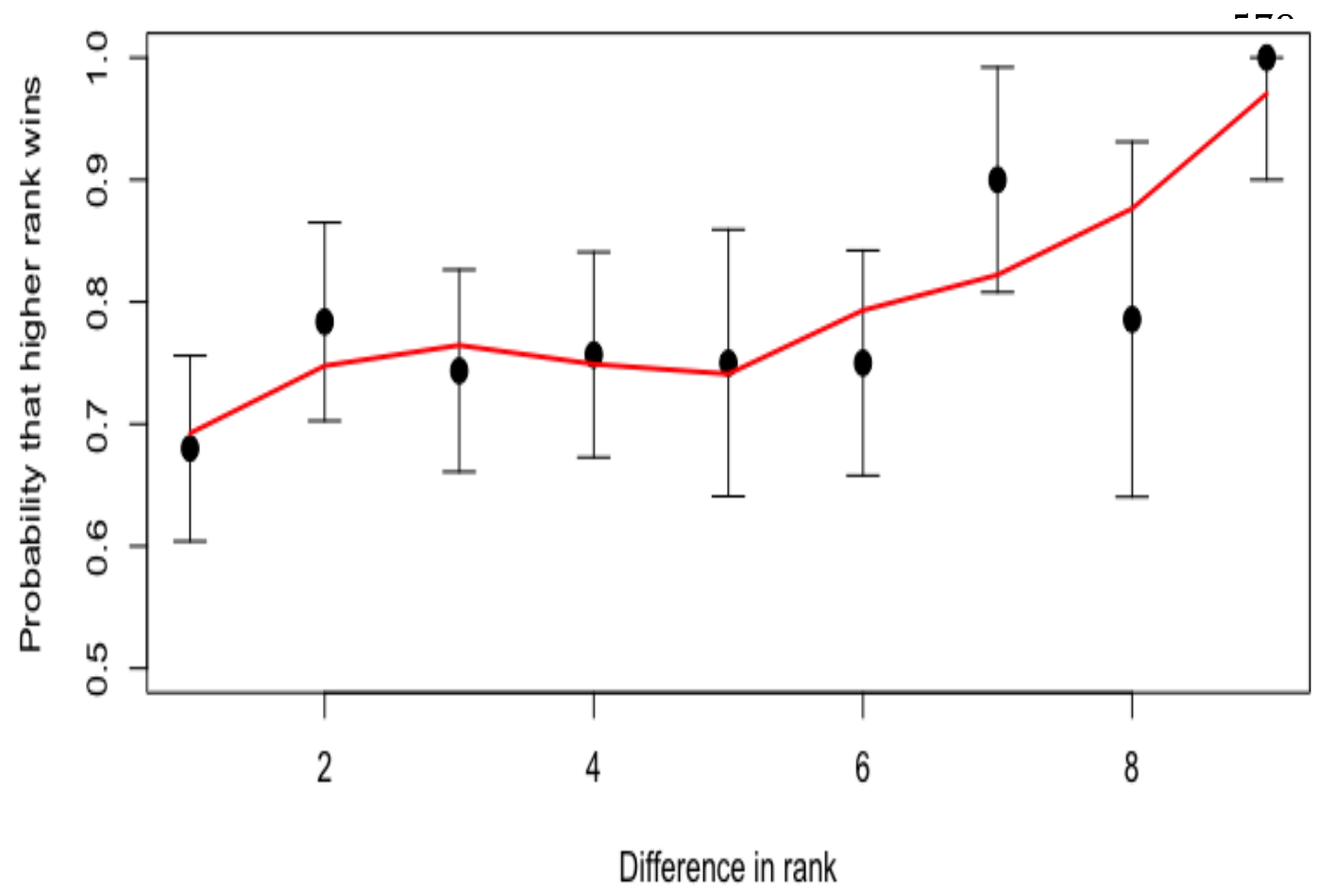


583 Figure 2. Triad census of twig-nesting arboreal ants. We determined the orderliness of

584 hierarchy by estimating the transitivity of interactions. The y-axis represents the mean difference

585 between the observed (ten ant species network) and expected (10,000 random networks)

586 percentage of the triad subtypes (shown on the x-axis) and error bars show $95 \%$ confidence

587 intervals. The twig-nesting ant data show a significant excess of transitive triads (transitive $=0.66$,

588 p-value $=0.002$ ) and a significant deficit of cyclical triads. All the other triad sub-types found

589 were not significantly different from the expected random network. The following symbols

590 define seven possible triad types: $A=$ Null, $B=$ Single-edge, $C=$ Double-dominance, $D=$ Double-

591 subordinate, $\mathrm{E}=$ Pass-along, $\mathrm{F}=$ Transitive, $\mathrm{G}=\mathrm{Cycle}$.

592

593

594

595

596

597

598

599

600

601

602

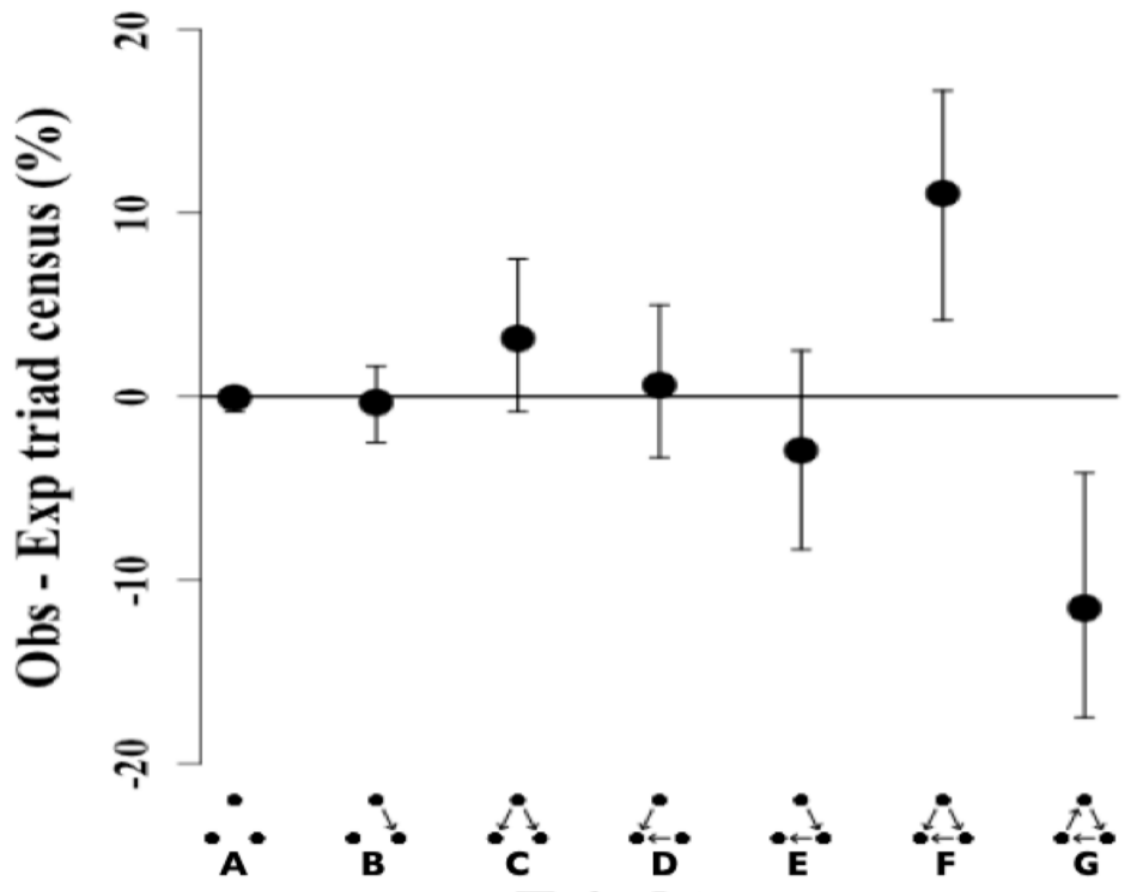

603

604

605 
bioRxiv preprint doi: https://doi org/10.1101/442632 this version posted October 13,2018 . The copyright holder for this preprint (which was not certified by peer review) is the author/funder, who has granted bioRxiv a license to display the preprint in perpetuity. It is made available under aCC-BY-NC-ND 4.0 International license.

606

607 